\title{
Stage I Cervical Cancer FIGO 2018
}

National Cancer Institute

\section{Source}

National Cancer Institute. Stage I Cervical Cancer FIGO 2018. NCI Thesaurus. Code

C162226.

The carcinoma is strictly confined to the cervix (extension to the uterine corpus should be disregarded). (FIGO 2018) 